\title{
Sagittal otolith size and shape variability to identify geographical intraspecific differences in three species of the genus Merluccius
}

\author{
Gabriel J. Torres*, Antoni Lombarte ${ }^{* \ddagger}$ and Beatriz Morales-Nin ${ }^{\dagger}$ \\ *Institut de Ciències del Mar (CSIC), PasseigJoan de Borbó s/n, 08039 Barcelona, Catalonia, Spain. 'Institut Mediterrani d’Estudis \\ Avançats (CSIC-UIB), Campus Universtari, 07071 Mallorca, Balearic Islands, Spain. \\ ${ }^{\ddagger}$ Corresponding author: E-mail: toni@icm.csic.es
}

\begin{abstract}
A study was carried out on the morphology (size and shape) of the saccular otolith (sagitta) by means of image analysis on three species of the genus Merluccius (M. gayi, M. hubbsi and M. merluccius). By digitization of the sagittae, morphometry and outline (Fourier harmonic) as form descriptor measurements were obtained, that were subsequently analysed by means of multivariant methods, allowing the intraspecific variability to be quantified. The differences in the intraspecific sagittal otolith variability confirmed spatial differences of predicted groups. The results were associated with environmental and population aspects. The use of combined morphometric measurements for the whole otolith and its corresponding sulcus acusticus were very appropriate for determining the origin of the analysed otoliths. Using both principal components analysis and discriminant analyses, a clear geographical differentiation was obtained for Merluccius gayi (from Chile and Peru) and M. merluccius (from the Atlantic and Mediterranean). In both species, the discriminant analysis predicted that all the sagittae could be correctly assigned within each of the groups studied. However, it was a little less effective at differentiating between the two groups of M. hubbsi (from the San Matias Gulf on the Patagonian Shelf and ArgentinianUruguayan Common Fishing Zone). As a result, the morphometric analysis of the sagittae otoliths acted as a clear diagnostic tool to differentiate individuals from different geographical distribution areas.
\end{abstract}

\section{INTRODUCTION}

The species of the genus Merluccius (Linneaus, 1758), denominated commonly as hakes, are extensively distributed in the Atlantic and Pacific oceans (Inada, 1981). The genus itself contributes to significant catches from the Gadiformes order that represent a quarter of the world catch of commercial marine fish (FAO, 1995). Fisheries management is based upon stocks or population units (Gulland, 1983). Thus, it is important to understand the significance and distribution of fish morphologies - as a stock or population unit of fish-and to determine if they are regulated by genetic or by phenotypic differences which reflect spatially separated environments (Casselman et al., 1981). There are several methods available to identify populations of fishes, based on meristic and morphometric characters (Côté et al., 1980; Casselmann et al., 1981) and on electrophoretical ones (Grant et al., 1987). For example, the shape and size of otoliths is affected by environmental and genetic variations (Nolf, 1985; Lombarte \& Lleonart, 1993; Torres et al., 1999). Otolith morphometrics have been used in several studies to identify species, geographical variations, populations and stocks of fish (Yefanov \& Khorevin, 1979; Messieh et al., 1989; Castonguay et al., 1991; Campana \& Casselman, 1993; Friedland \& Reddin, 1994; Levi et al., 1994).

In previous studies, most species of the genus Merluccius have shown interspecific morphological differences in their sagittal otoliths (Lombarte \& Castellón, 1991) and in their respective sulcus acusticus (Torres et al., 1999). Nevertheless, the intraspecific variability of both the sagitta and sulcus acusticus is not yet known.

In this study, geographical intraspecific variations were analysed regarding the morphology (size and shape) of the sagittae otoliths from three species of the genus Merluccius: M. gayi (Guichenot, 1848), M. hubbsi (Marini, 1933) and M. merluccius (Linneaus, 1758). These species were selected because they show distinct geographic and population characteristics, therefore they can reflect the possible causes of otolith variability. Merluccius gayi is found in the south-eastern Pacific, and it is at present recognized as two subspecies, M. g. gayi and M. g. peruanus (Cohen et al., 1990), which are distributed in two geographically isolated areas with differentiated oceanographic conditions (Aguayo-Hernández, 1995; Espino et al., 1995). The species $M$. hubbsi was studied since it is a single genetic population but has a high heterozygosity (Roldán, 1991). This heterozygosity and the continuous distribution range of $M$. hubssi in different oceanographic environments (Angelescu \& Prenski, 1987) results in problems of stock identification (Roldán, 1991; Torres et al., 1996). Finally, M. merluccius was chosen because genetic differences between the populations have led to the formation of a cline from the Atlantic ocean to the eastern end of the Mediterranean Sea. In addition, the above species is distributed in very differentiated environments (the north-eastern Atlantic and Mediterranean Sea). However, as opposed to M. gayi, the genetic studies carried out on M. merluccius indicate the 
existence of a genetic flow between both geographic groups (Roldán et al., 1998).

\section{MATERIALS AND METHODS}

For each studied species two geographically separate samples were analysed. The specimens of Merluccius gayi came from the coasts of Peru and Chile. The otoliths of
M. hubbsi came from the Argentinian-Uruguayan Common Fishing Zone (AUCFZ) and the San Matias Gulf (SMG) on the Patagonian Shelf. The samples of M. merluccius came from the Central Atlantic Ocean (Cantabrian Sea) off the coasts of Northern Spain and the Gulf of Lions in the north-western Mediterranean (Figure 1). A total of 203 right sagittal otoliths were digitized and analysed. Localities, otolith sample size and the
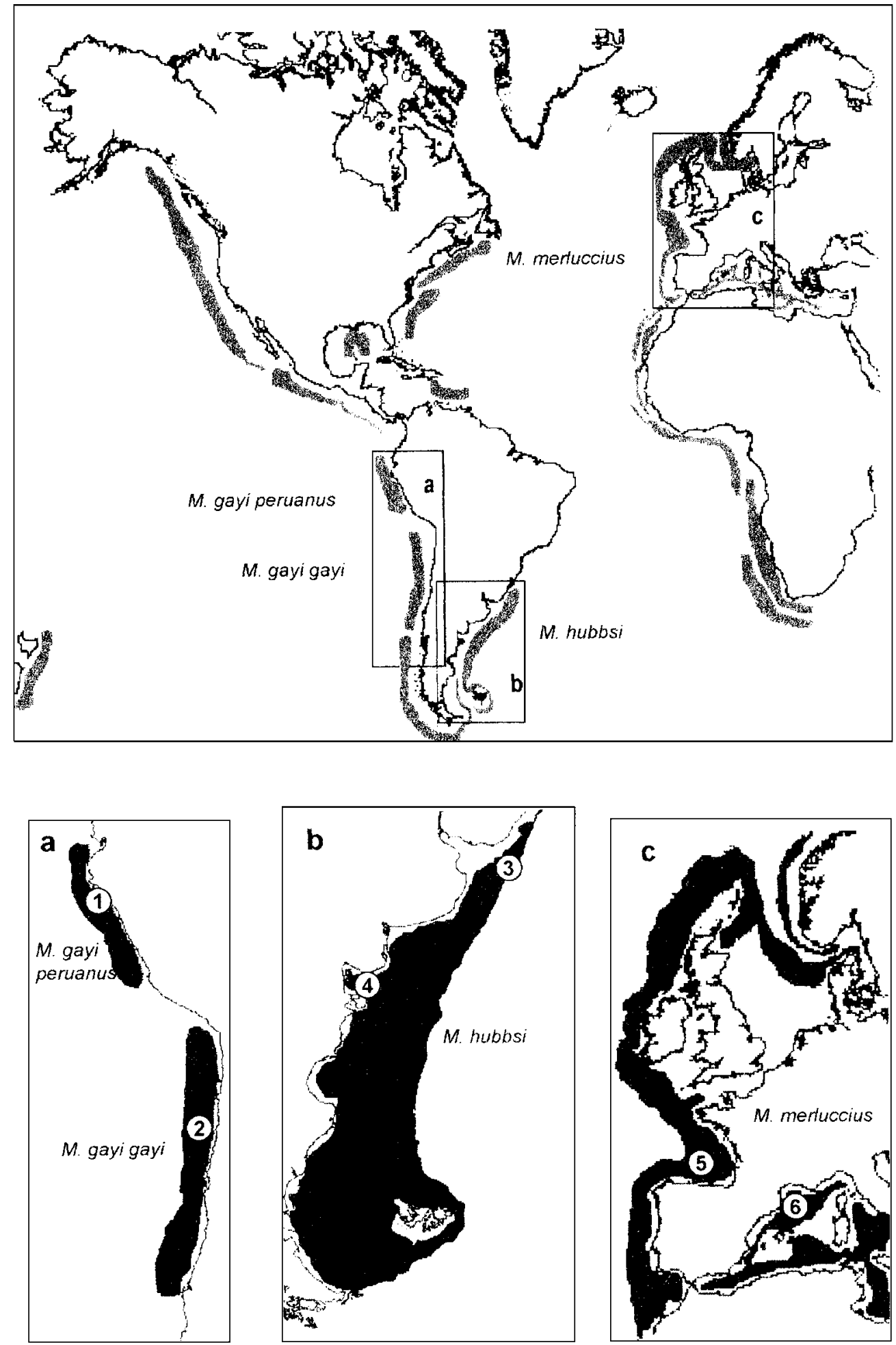

Figure 1. World geographical distribution areas of the genus Merluccius based on Inada (1981) and Pitcher \& Alheit (1995), indicating the three species in this study. Otolith samples for both M. gayi peruanus (a1) and M. gayi gayi (a2) from Peru and Chile respectively; for M. hubbsi from the AUFCZ (b3) and San Matias Gulf (b4) respectively, and for M. merluccius from the Cantabrian Sea (c5) and the north-western Mediterranean (c6) respectively. 
Table 1. Number of otoliths digitized by species, group origins and size range of fish sampled in Merluccius.

\begin{tabular}{|c|c|c|c|}
\hline Species & From & $\begin{array}{l}\text { Number } \\
\text { of otoliths } \\
\text { digitized }\end{array}$ & $\begin{array}{l}\text { Size range } \\
\text { of fish } \\
(\mathrm{cm})\end{array}$ \\
\hline M. gayiperuanus & $\begin{array}{l}\text { South-eastern Pacific } \\
\text { (Peru) }\end{array}$ & 29 & $35-84$ \\
\hline M. gayi gayi & $\begin{array}{l}\text { South-eastern Pacific } \\
\text { (Chile) }\end{array}$ & 30 & $8-108$ \\
\hline M. merluccius & $\begin{array}{l}\text { North-eastern Atlantic } \\
\text { (Cantabrian Sea) }\end{array}$ & 28 & $21-70$ \\
\hline M. merluccius & $\begin{array}{l}\text { Mediterranean Sea (Gulf } \\
\text { of Lion) }\end{array}$ & 30 & $14-77$ \\
\hline M. hubbsi & $\begin{array}{l}\text { South-western Atlantic } \\
\text { (Argentinian-- } \\
\text { Uruguayan Common } \\
\text { Fishing Zone) }\end{array}$ & 56 & $14-87$ \\
\hline M. hubbsi & $\begin{array}{l}\text { South-western Atlantic } \\
\text { (San Matias Gulf) }\end{array}$ & 29 & $15-61$ \\
\hline
\end{tabular}

fish length range for the samples are shown in Table 1. Morphological measurements were made by digitizing the images of the sagittae otoliths with a high-resolution TV camera coupled to a binocular microscope and a PG. Image analysis and processing was carried out using the Morphos routine in the Kronomorphos program (Morales-Nin et al., 1998a).

Two kinds of otolith variables were considered in order to compare the two methods described below and analyse jointly the results obtained to gain a better understanding of otolith intraspecific variability.

Firstly, to compare size and shape patterns, 13 morphological features were selected which corresponded to five biometric measurements on the whole sagittae and the remaining eight to the sulcus acusticus (Table 2). To carry out morphometrical analyses, body size and allometric effects that occur during otolith growth were avoided by normalizing all measurements to a standard otolith size taking into account the allometric relationship (Lombarte \& Lleonart, 1993). For each of the 13 morphologic measurements the allometric relationship with fish body length was calculated. The equation used was the standard $Y=a X^{b}$, fitted using logarithmic transformation to homogenize the residuals. Each measurement $Y$ was transformed into $Z$, according to $Z=r\left(X_{0} / X\right)^{b}$, where $X$ is the otolith length of the sample, and $X_{0}$ is the total reference fish body length. Based on the median value of fish length, a $40 \mathrm{~cm}$ standard reference $\left(X_{0}\right)$ was selected for standardization.

Secondly, shape in terms of outline by Fourier Analysis (also called Harmonic Analysis in mathematics) was applied to study the otolith shape. This last method has practical importance due to its robustness and independence of the unit of measurement. It should be borne in mind that the study of sagittal otolith shape variability should consider the measurement of shape independently of otolith size and vice versa. In this sense, Fourier's harmonics describe the polar co-ordinates that are derived from the outline, providing a convenient intermediate measurement of the shape, thereby allowing twodimensional representation in terms of the co-ordinates at the origin (O'Higgins \& Williams, 1987). The first 20 amplitudes obtained were used as otolith shape descriptors, although only 19 of them were considered (the zero origin ones were not counted). To eliminate changes in otolith shape with increasing size, the amplitudes were standardized by dividing each one by the amplitude 0 (Castonguay et al., 1991; Torres et al., 1999).

Multivariate morphometric analysis is a quantitative tool used to describe biological structures (Macleod \& Kitchell, 1990), and it was applied in order to compare intraspecific morphological variability in the sagittae otoliths of the Merluccius species mentioned above.

The principal components analysis (PCA) used in this study was carried out from the correlation matrix $(\mathrm{R})$ from the standardized morphometric variables (first type of otolith variable), which is described as a size and shape analysis. The main reason for the use of the correlation matrix is that it makes the principal components independent of the order of magnitude and the scale of the variable measurements (Jolicoeur, 1963). For the otolith shape descriptor comparisons ANOVA was used because the shape variables (Fourier harmonics) as shape descriptors were uncorrelated.

To identify intraspecific populations and stocks from different geographical origins, linear discriminant function (LDF) and quadratic discriminant function (QDF) were used for both morphometric variables (a pool of 13 morphometric measurements and otolith shape descriptors), based on size and shape and shape analysis respectively. Linear discriminant function is an appropriate analysis when the two populations have identical variance-covariance matrices. The quadratic discriminant function is the appropriate analysis for populations that differ in their dispersion matrices (Misra, 1985).

\section{RESULTS}

The means and standard deviations of standardized morphometric measurements are indicated in Table 2 and the means of the Fourier harmonics are represented for each analysed group in Figure 2. The analyses carried out from the morphometric measurements and from the external outlines of the sagittae of each species are described below.

\section{Merluccius gayi}

The PCA analysis (Figure 3A) revealed a distribution gradient for the sagittae. Merluccius gayi gayi samples appeared at one end of the gradient, and those of $M$. gayi peruanus at the other. The first principal component explained $82.22 \%$ of the variability and all the coefficients of the morphometric variables, which were all positive, appeared highly correlated with this component (Table 3). These results indicated the existence of differences in the relative size of the otoliths, with $M$. gayi peruanus being characterized by the largest relative size (Table 2). The second principal component (6.50\%) showed positive and negative tendencies in its coefficients, with the most conspicuous of the latter being caudal colliculum maximum height and the collum vertical height (Table 3). The linear discriminant analysis from the morphometric measurements showed significant 
Table 2. Means and standard deviations of the otolith morphometries of the three Merluccius species studied.

\begin{tabular}{|c|c|c|c|c|c|}
\hline \multirow[b]{2}{*}{ A. $M \cdot$ gayi } & \multirow[b]{2}{*}{ Var. Group } & \multicolumn{2}{|c|}{ Peru } & \multicolumn{2}{|c|}{ Chile } \\
\hline & & Mean & $\mathrm{SD}$ & Mean & SD \\
\hline & $\begin{array}{l}\text { Sagittal otolith } \\
\text { area }\left(\mathrm{mm}^{2}\right) \\
\text { perimeter }(\mathrm{mm}) \\
\text { convex perimeter }(\mathrm{mm}) \\
\text { maximum length }(\mathrm{mm}) \\
\text { maximum height }(\mathrm{mm})\end{array}$ & $\begin{array}{r}86.80 \\
107.79 \\
40.25 \\
18.77 \\
6.95\end{array}$ & $\begin{array}{l}7.39 \\
6.85 \\
2.37 \\
1.20 \\
0.41\end{array}$ & $\begin{array}{r}64.04 \\
92.89 \\
34.44 \\
16.07 \\
6.13\end{array}$ & $\begin{array}{r}10.25 \\
7.05 \\
2.18 \\
1.05 \\
0.59\end{array}$ \\
\hline & $\begin{array}{l}\text { Sulcus acusticus } \\
\text { area }\left(\mathrm{mm}^{2}\right) \\
\text { perimeter }(\mathrm{mm}) \\
\text { convex perimeter }(\mathrm{mm}) \\
\text { maximum length }(\mathrm{mm}) \\
\text { max. height caudal colliculum }(\mathrm{mm}) \\
\text { maximum height collum }(\mathrm{mm}) \\
\text { collum caudal colliculum length }(\mathrm{mm}) \\
\text { collum ostial colliculum length }(\mathrm{mm})\end{array}$ & $\begin{array}{r}31.51 \\
32.52 \\
29.90 \\
14.34 \\
3.15 \\
1.28 \\
7.99 \\
6.31\end{array}$ & $\begin{array}{l}4.82 \\
2.87 \\
2.33 \\
1.14 \\
0.34 \\
0.20 \\
0.68 \\
0.56\end{array}$ & $\begin{array}{r}21.37 \\
27.20 \\
25.36 \\
12.33 \\
2.62 \\
1.00 \\
6.76 \\
5.43\end{array}$ & $\begin{array}{l}5.17 \\
2.84 \\
2.50 \\
1.15 \\
0.41 \\
0.21 \\
0.82 \\
0.59\end{array}$ \\
\hline & & & & San 1 & Gulf \\
\hline \multirow[t]{3}{*}{ B. M. hubbsi } & Var. Group & Mean & SD & Mean & SD \\
\hline & $\begin{array}{l}\text { Sagittal otolith } \\
\text { area }\left(\mathrm{mm}^{2}\right) \\
\text { perimeter }(\mathrm{mm}) \\
\text { convex perimeter }(\mathrm{mm}) \\
\text { maximum length }(\mathrm{mm}) \\
\text { maximum height }(\mathrm{mm}) \\
\text { Sulcus acusticus } \\
\text { area }\left(\mathrm{mm}^{2}\right) \\
\text { perimeter }(\mathrm{mm}) \\
\text { convex perimeter }(\mathrm{mm}) \\
\text { maximum length }(\mathrm{mm}) \\
\text { max. height caudal colliculum }(\mathrm{mm}) \\
\text { maximum height collum }(\mathrm{mm}) \\
\text { collum caudal colliculum length }(\mathrm{mm}) \\
\text { collum ostial colliculum length }(\mathrm{mm})\end{array}$ & $\begin{array}{r}80.60 \\
101.59 \\
37.91 \\
17.69 \\
6.82 \\
\\
24.39 \\
29.84 \\
27.89 \\
13.47 \\
2.72 \\
1.06 \\
7.79 \\
5.69\end{array}$ & $\begin{array}{c}13.16 \\
8.47 \\
3.09 \\
1.40 \\
0.60 \\
\\
4.84 \\
3.27 \\
2.86 \\
1.30 \\
0.38 \\
0.28 \\
0.97 \\
0.81\end{array}$ & $\begin{array}{r}83.15 \\
102.12 \\
38.51 \\
17.93 \\
6.98 \\
\\
23.42 \\
30.02 \\
28.02 \\
13.60 \\
2.55 \\
1.02 \\
7.93 \\
5.47\end{array}$ & $\begin{array}{l}2.97 \\
2.28 \\
1.99 \\
0.98 \\
0.25 \\
0.20 \\
0.68 \\
0.51\end{array}$ \\
\hline & & & & $\mathrm{Med}$ & ean \\
\hline \multirow[t]{3}{*}{ C. M. merluccius } & Var. Group & Mean & SD & Mean & SD \\
\hline & $\begin{array}{l}\text { Sagittal otolith } \\
\text { area }\left(\mathrm{mm}^{2}\right) \\
\text { perimeter }(\mathrm{mm}) \\
\text { convex perimeter }(\mathrm{mm}) \\
\text { maximum length }(\mathrm{mm}) \\
\text { maximum height }(\mathrm{mm})\end{array}$ & $\begin{array}{c}80.115 \\
102.018 \\
37.58 \\
17.71 \\
6.754\end{array}$ & $\begin{array}{l}4.347 \\
4.409 \\
1.611 \\
0.651 \\
0.221\end{array}$ & $\begin{array}{r}102.785 \\
111.888 \\
42.674 \\
19.665 \\
7.669\end{array}$ & $\begin{array}{l}7.218 \\
4.508 \\
1.701 \\
0.744 \\
0.354\end{array}$ \\
\hline & $\begin{array}{l}\text { Sulcus acusticus } \\
\text { area }\left(\mathrm{mm}^{2}\right) \\
\text { perimeter }(\mathrm{mm}) \\
\text { convex perimeter }(\mathrm{mm}) \\
\text { maximum length }(\mathrm{mm}) \\
\text { max. height caudal colliculum }(\mathrm{mm}) \\
\text { maximum height collum }(\mathrm{mm}) \\
\text { collum caudal colliculum length }(\mathrm{mm}) \\
\text { collum ostial colliculum length }(\mathrm{mm})\end{array}$ & $\begin{array}{r}24.273 \\
30.664 \\
28.196 \\
13.694 \\
2.739 \\
0.835 \\
8.334 \\
5.359\end{array}$ & $\begin{array}{l}3.815 \\
1.662 \\
1.507 \\
0.731 \\
0.325 \\
0.224 \\
0.504 \\
0.415\end{array}$ & $\begin{array}{r}27.798 \\
33.098 \\
30.792 \\
14.905 \\
2.846 \\
1.061 \\
9.366 \\
5.522\end{array}$ & $\begin{array}{l}3.2 \\
1.722 \\
1.509 \\
0.764 \\
0.221 \\
0.223 \\
0.596 \\
0.543\end{array}$ \\
\hline
\end{tabular}

differences between both groups (Wilk's lambda $=0.1628$; approximate $\left.F_{(13,43)}=16.997 ; \quad P<0.001\right)$. This analysis assigned a correct classification probability to each subspecies in the prediction of $100 \%$ (Table $4 \mathrm{~A}$ ).
Due to the fact that the shape variables (Fourier harmonics) were uncorrelated a one-way ANOVA was carried out, that indicated harmonics 4, 8, 11, 12 and 14 were significant $\left(F_{(0.05,1,57)} ; P<0.05\right)$ (Table 5). 

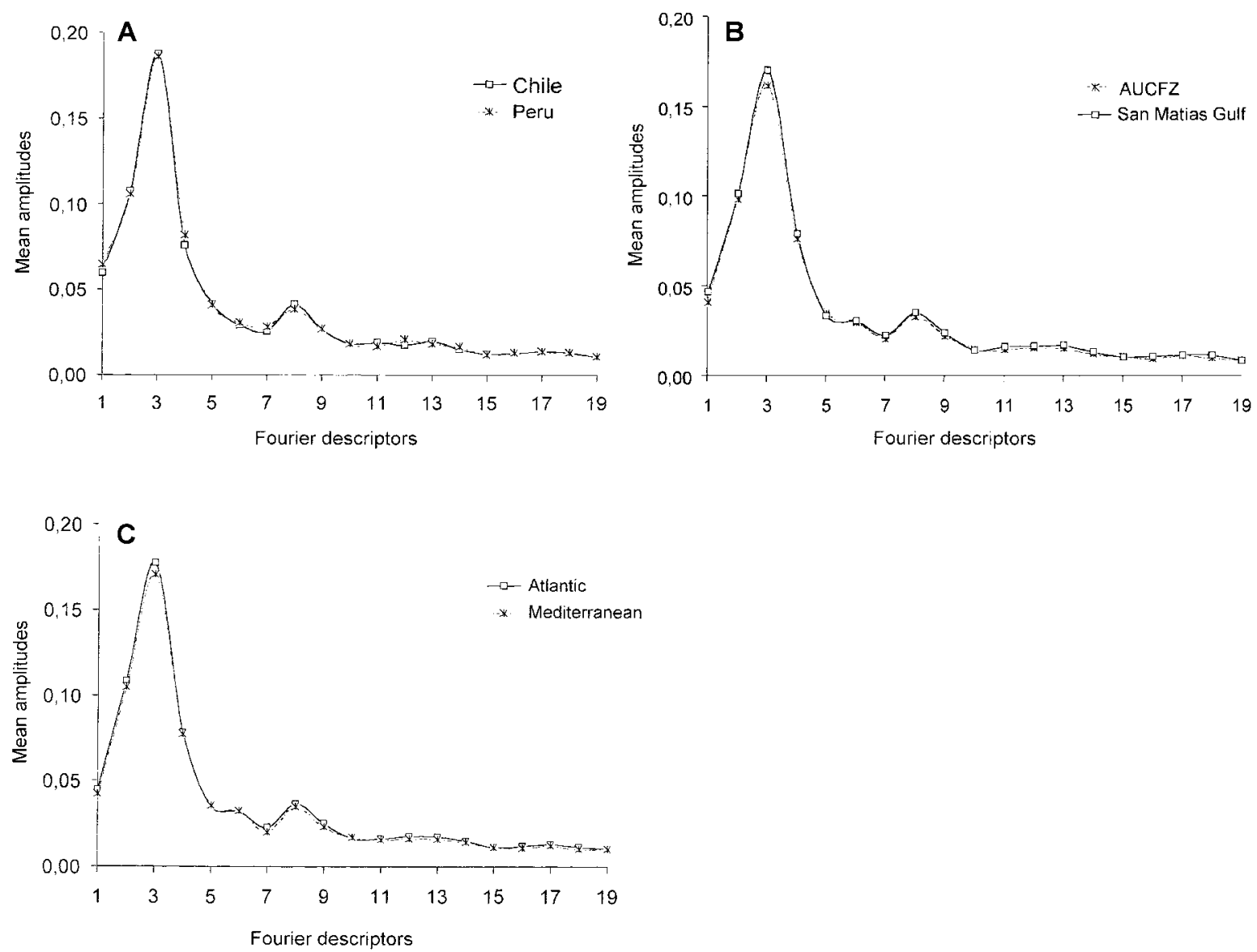

Figure 2. Mean amplitude spectra of otoliths from three species of the genus Merluccius. (A) Merluccius gayi, (B) M. hubbsi and (C) M. merluccius.
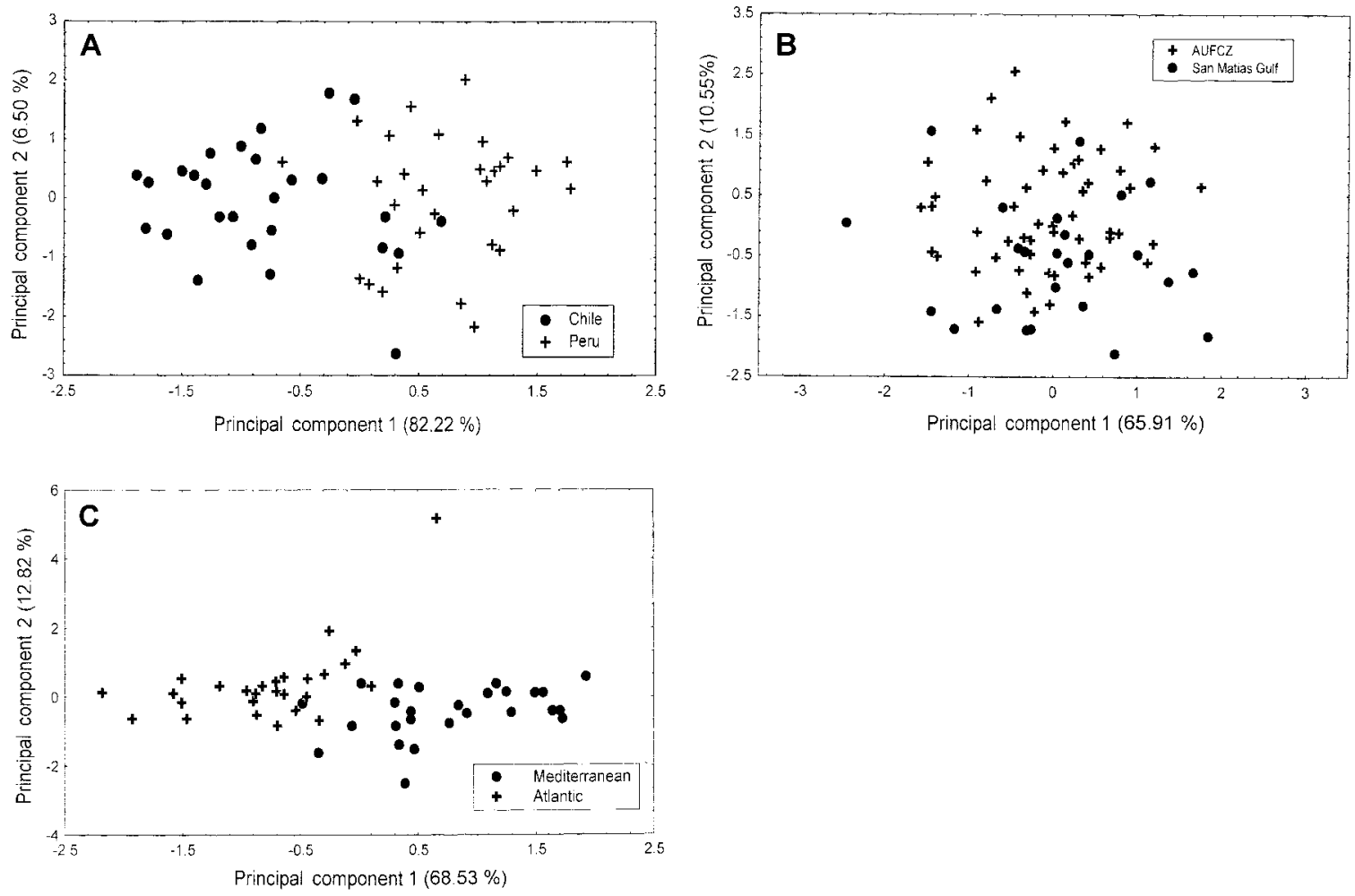

Figure 3. Size and shape analysis. Scatterplot of factor scores from the intraspecific principal components analysis of three species: (A) M. gayi, (B) M. hubbsi and (C) Merluccius merluccius. 
Table 3. Factor loadings. Intraspecific variability of sagittal otoliths for three analysed species. Size and shape analysis.

\begin{tabular}{|c|c|c|c|c|c|c|}
\hline \multirow[b]{2}{*}{ Variables/species } & \multicolumn{2}{|c|}{ Merluccius gayi } & \multicolumn{2}{|c|}{ Merluccius hubbsi } & \multicolumn{2}{|c|}{ Merluccius merluccius } \\
\hline & $\mathrm{PCl}$ & PC2 & $\mathrm{PCl}$ & $\mathrm{PC} 2$ & $\mathrm{PCl}$ & PC2 \\
\hline \multicolumn{7}{|l|}{ Sagittal otolith } \\
\hline area & 0.942 & 0.143 & 0.890 & -0.216 & 0.883 & -0.364 \\
\hline perimeter & 0.979 & 0.136 & 0.980 & -0.022 & 0.982 & -0.070 \\
\hline convex perimeter & 0.914 & 0.271 & 0.791 & -0.300 & 0.879 & -0.427 \\
\hline maximum length & 0.918 & 0.306 & 0.901 & -0.205 & 0.898 & -0.361 \\
\hline maximum height & 0.840 & -0.035 & 0.781 & -0.219 & 0.815 & -0.347 \\
\hline \multicolumn{7}{|l|}{ Sulcus acusticus } \\
\hline area & 0.949 & -0.266 & 0.859 & 0.447 & 0.823 & 0.485 \\
\hline perimeter & 0.933 & -0.059 & 0.930 & -0.019 & 0.931 & 0.098 \\
\hline convex perimeter & 0.973 & 0.081 & 0.941 & 0.022 & 0.947 & 0.072 \\
\hline maximum length & 0.971 & 0.102 & 0.951 & -0.038 & 0.940 & 0.097 \\
\hline max. height caudal colliculum & 0.776 & -0.507 & 0.580 & 0.583 & 0.562 & 0.672 \\
\hline maximum height collum & 0.724 & -0.518 & 0.137 & 0.763 & 0.531 & 0.401 \\
\hline collum caudal colliculum length & 0.926 & 0.134 & 0.830 & -0.063 & 0.882 & -0.093 \\
\hline collum ostial colliculum length & 0.897 & 0.008 & 0.572 & 0.119 & 0.463 & 0.461 \\
\hline Eigenvalues & 10.688 & 0.845 & 8.568 & 1.372 & 8.909 & 1.667 \\
\hline Percent. variance & 82.22 & 6.50 & 65.91 & 10.55 & 68.53 & 12.82 \\
\hline
\end{tabular}

Table 4. (A) Linear discriminant analysis. Classification matrix of sagittal otoliths for Merluccius gayi peruanus (Peru) and M. gayi gayi (Chile); for M. hubbsi from both the Argentinian-Uruguayan Common Fishing Zone (AUCFZ) (samplings taken at latitude $41^{\circ}-42^{\circ} S$ ) and San Matias Gulf ( $S M G$ ) (northern stock from samplings taken at latitude $\mathcal{N}$ of $36^{\circ} S$ ); for M. merluccius from both the north-eastern Atlantic (NE Atlantic) and Mediterranean (Mediter) respectively. (B) Quadratic discriminant analysis. Classification matrix of sagittal otoliths for M. hubbsi from both the Argentinian-Uruguayan Common Fishing Zone (AUCFZ) and San Matias Gulf (SMG). In basis to morphometrics measurements employed in size and shape analysis.

A.

B.

\begin{tabular}{|c|c|c|c|c|c|}
\hline \multirow[b]{2}{*}{ Actual } & \multicolumn{2}{|c|}{ Predicted classification } & \multirow[b]{2}{*}{ Actual } & \multicolumn{2}{|c|}{ Predicted classification } \\
\hline & Peru & Chile & & AUCFZ & SMG \\
\hline $\begin{array}{l}\text { Peru } \\
\text { Chile }\end{array}$ & $\begin{array}{l}30(100 \%) \\
0 \\
\mathrm{NIMC}^{1}: 0 ; \mathrm{PMC}^{2}: 0\end{array}$ & $\begin{array}{l}0 \\
27(100 \%)\end{array}$ & $\begin{array}{l}\text { AUCFZ } \\
\text { SMG }\end{array}$ & $\begin{array}{l}55(96.49 \%) \\
3(10.71 \%) \\
\text { NIMG }^{1}: 5 ; \text { PMC }^{2}: 0.058\end{array}$ & $\begin{array}{l}2(3.51 \%) \\
25(89.29 \%)\end{array}$ \\
\hline $\begin{array}{l}\text { AUCFZ } \\
\text { SMG }\end{array}$ & $\begin{array}{l}\text { AUCFZ } \\
53(92.98 \%) \\
9(32.14 \%) \\
\text { NIMC }^{1}: 13 ; \mathrm{PMC}^{2}: 0.153\end{array}$ & $\begin{array}{l}\text { SMG } \\
4(7.02 \%) \\
19(67.86 \%)\end{array}$ & & & \\
\hline $\begin{array}{l}\text { NE Atlantic } \\
\text { Mediter }\end{array}$ & $\begin{array}{l}\text { NE Atlantic } \\
28(100 \%) \\
0 \\
\text { NIMC }^{1}: 0 ; \mathrm{PMC}^{2}: 0\end{array}$ & $\begin{array}{l}\text { Mediter } \\
0 \\
28(100 \%)\end{array}$ & & & \\
\hline
\end{tabular}

${ }^{1}$, Number of misclassified individuals; ${ }^{2}$, probability of mistaken classification.

Consequently, they were those that better discriminated the Chile and Peru groups (Figure 2A). The linear discriminant analysis gave significant differences (Wilk's lambda $=0.3252 ;$ approximate $\left.F_{(19,39)}=4.260 ; \quad P<0.001\right)$ and it assigned a correct classification probability in predicting $93.10 \%$ of the $M$. gayi peruanus subspecies and $86.67 \%$ of the M. gayi gayi subspecies (Table 6A).
However, the quadratic analysis, that also gave significant differences (Chi-Square test: $\chi_{(190)}^{2}=375.91$; $P<0.001$ ), offered a better fit, since the probability of mistaken classification (PMC) and the number of misclassified individuals (NIMG) were lower than for the LDF. It correctly assigned all the individuals of $M$. gayi peruanus to this group and improved the 
Table 5. ANOVA of Fourier's harmonics variables descriptors analysis. Univariate tests. Shape analysis of three species.

\begin{tabular}{|c|c|c|c|c|c|c|}
\hline \multirow[b]{2}{*}{ Harm./species } & \multicolumn{2}{|c|}{ Merluccius gayi } & \multicolumn{2}{|c|}{ Merluccius hubbsi } & \multicolumn{2}{|c|}{ Merluccius merluccius } \\
\hline & $\mathrm{F}$ & Signif. of $F$ & $\mathrm{~F}$ & Signif. of F & $\mathrm{F}$ & Signif. of F \\
\hline 1 & 1.150 & 0.288 & 7.509 & $0.008 * *$ & 1.699 & 0.198 \\
\hline 2 & 0.729 & 0.396 & 5.735 & $0.019 * *$ & 7.629 & $0.008 * * *$ \\
\hline 3 & 0.181 & 0.672 & 12.585 & $0.001 * *$ & 9.120 & $0.004 * * *$ \\
\hline 4 & 5.529 & $0.022 *$ & 2.030 & 0.158 & 0.282 & 0.597 \\
\hline 5 & 0.216 & 0.643 & 1.129 & 0.291 & 0.041 & 0.839 \\
\hline 6 & 1.404 & 0.241 & 2.209 & 0.141 & 0.037 & 0.847 \\
\hline 7 & 1.854 & 0.179 & 2.553 & 0.114 & 6.106 & $0.017 * * *$ \\
\hline 8 & 5.449 & $0.023^{*}$ & 11.709 & $0.001 * *$ & 4.625 & $0.036 * * *$ \\
\hline 9 & 0.193 & 0.661 & 4.021 & $0.048 * *$ & 6.843 & $0.011 * * *$ \\
\hline 10 & 0.001 & 0.971 & 0.017 & 0.895 & 1.317 & 0.256 \\
\hline 11 & 10.173 & $0.002 *$ & 12.299 & $0.001 * *$ & 2.593 & 0.113 \\
\hline 12 & 14.866 & $0.000^{*}$ & 3.771 & 0.056 & 8.238 & $.006 * * *$ \\
\hline 13 & 3.933 & 0.052 & 12.481 & $0.001 * *$ & 10.402 & $0.002 * * *$ \\
\hline 14 & 7.181 & $0.010^{*}$ & 3.817 & 0.054 & 3.703 & 0.059 \\
\hline 15 & 1.079 & 0.303 & 0.503 & 0.480 & 0.000 & 0.995 \\
\hline 16 & 0.550 & 0.461 & 11.028 & $0.001 * *$ & 6.912 & $0.011 * * *$ \\
\hline 17 & 0.282 & 0.597 & 1.429 & 0.235 & 7.824 & $0.007 * * *$ \\
\hline 18 & 0.052 & 0.819 & 19.235 & 0.001 & 13.750 & $0.000 * * *$ \\
\hline 19 & 0.805 & 0.373 & 1.466 & 0.229 & 0.000 & 0.982 \\
\hline
\end{tabular}

*, Significant value, $\alpha=0.05$, fd.: 1, 57;**, Significant value, $\alpha=0.05$, fd.: 1, 38; ***, Significant value, $\alpha=0.05$, fd.: 1,56 .

prediction of the classification of individuals belonging to $M$. gayi gayi by $10 \%$ (Table $6 \mathrm{~B}$ ).

\section{Merluccius hubbsi}

In the PCA carried out on the sagittae of M. hubbsi (Figure 3B), the first principal component explained $65.91 \%$ of the variability. Since all the coefficients were positive, as for M. gayi, and almost all the morphometric variables were highly correlated with this component (Table 3), we could attribute this variability to differences in the relative size of the otoliths. However, unlike the other two studied species, the sagittae of both groups were not clearly separated and no trends were found. The second principal component explained $10.55 \%$ of the variability and it gave positive and negative coefficients (Table 3). The variables had greater correlation with the variability expressed by the second component, and were linked to the morphology of the sulcus acusticus, corresponding to the variables of collum maximum height, caudal colliculum maximum height and area. The linear discriminant analysis showed significant differences between the groups (Wilk's lambda $=0.6415$; approximate $\left.F_{(13,71)}=3.051 ; P<0.001\right)$ but it had a high probability of mistaken otolith classification, which did not happen in the other studied species (Table 4A). The quadratic discriminant analysis (Chi-Square test: $\chi^{2}{ }_{(91)}=123.88 ; P<0.001$ ) improved this substantially and a better classification prediction was obtained for both groups (Table 4B).

The one-way analysis of variance (ANOVA) (Table 5) indicated that the intergroup differences of the Fourier harmonics 1, 2, 3, 8, 9, 11, 13, 16 and 18 were significant and therefore they discriminated both groups (Figure 2B). The linear discriminant analysis that gave significant differences between the groups (Wilk's lambda $=0.625$; approximate $\left.F_{(19,65)}=2.05 ; \quad P<0.001\right)$, also assigned a slightly high probability of mistaken classification for the otoliths (Table 6A). However, the quadratic discriminant analysis, that also gave significant differences (Chi-Square test: $\left.\chi_{(190)}^{2}=349.696 ; P<0.001\right)$, showed a better fit, although there were a number of misclassified otoliths, and a smaller probability of mistaken classification than in the previous analysis. A correct prediction of $100 \%$ for the sagittae of the San Matias Gulf was noted and the quadratic discriminant analysis improved the prediction for the ArgentineUruguayan Fishery Common Zone group by 5\% (Table 6B).

\section{Merluccius merluccius}

In the PCA for the study of the M. merluccius species (north-eastern Atlantic and Mediterranean Sea) (Figure $3 \mathrm{C}$ ), a gradient was observed in the arrangement of the sagittae that placed the Atlantic M. merluccius at one end, and the Mediterranean M. merluccius at the opposite end. In the first principal component $(68.53 \%$ of the total variability), we observed that all the coefficients were positive, and that almost all the morphometric variables were highly correlated with this component (Table 3). These results indicated that the differences between the two groups were related to the greater relative size of the morphometric measurements of the otoliths from the Mediterranean (Table 2). The second principal component $(12.82 \%)$ showed positive and negative coefficients (Table 3 ) and the variables with a larger positive correlation were linked to the morphology of the sulcus acusticus, which were area, caudal colliculum maximum height and collum-colliculum ostial length. On the other hand, the variables with larger negative correlation were total area, convex perimeter, maximum length and maximum height of the otolith related to the relative size of the sagitta. The linear discriminant 
Table 6. (A) Linear discriminant analysis. Classification matrix of sagittal otoliths for Merluccius gayi peruanus (Peru) and M. gayi gayi (Chile); for M. hubbsi from both the Argentinian-Uruguayan Common Fishing Zone (AUCFZ) and San Matias Gulf (SMG); for M. merluccius from both the north-eastern Atlantic (NE Atlantic) and Mediterranean (Mediter) respectively. (B) Quadratic discriminant analysis. Classification matrix of sagittal otoliths from the above same three species and groups. In basis to Fourier's harmonics used in shape analysis.

A.

\begin{tabular}{lll}
\hline & \multicolumn{2}{c}{ Predicted classification } \\
\cline { 2 - 3 } Actual & Peru & Chile \\
\hline Peru & $27(93.10 \%)$ & $2(6.90 \%)$ \\
Chile & $4(13.33 \%)$ & $26(86.67 \%)$ \\
& NIMC $^{1}: 6 ;$ PMC $^{2}: 0.10$ & \\
& AUCFZ & SMG \\
AUCFZ & $51(91.07 \%)$ & $5(8.93 \%)$ \\
SMG & $14(48.28 \%)$ & $15(51.72 \%)$ \\
& NIMC $119 ;$ PMC $^{2}: 0.25$ & \\
& NE Atlantic & Mediter \\
NE Atlantic & $26(92.86 \%)$ & $2(7.14 \%)$ \\
Mediter & 0 & $30(100 \%)$ \\
& NIMC ${ }^{1}: 2 ;$ PMC $^{2}: 0.034$ & \\
\hline
\end{tabular}

1, Number of misclassified individuals; ${ }^{2}$, probability of mistaken classification.

B.

Predicted classification

\begin{tabular}{lll}
\cline { 3 - 3 } Actual & Peru & Chile \\
\hline Peru & $29(100 \%)$ & 0 \\
Chile & $1(3.33 \%)$ & $29(96.66 \%)$ \\
& NIMC $^{1}: 1 ;$ PMC $^{2}: 0.017$ & \\
& AUCFZ & SMG \\
AUCFZ & $54(96.40 \%)$ & $2(3.60 \%)$ \\
SMG & 0 & $29(100 \%)$ \\
& NIMC $1: 2 ;$ PMC $^{2}: 0.024$ & \\
& NE Atlantic & Mediter \\
NE Atlantic & $28(100 \%)$ & 0 \\
Mediter & 0 & $30(100 \%)$ \\
& NIMC $^{1}: 0 ;$ PCE $^{2}: 0$ & \\
\hline
\end{tabular}

${ }^{1}$, Number of misclassified individuals $;{ }^{2}$, probability of mistaken classification.

analysis, that gave significant differences (Wilk's lambda $=0.1260$; approximate $F_{(13,42)}=22,3997 ; P<0.001$ ), assigned a correct classification probability for the prediction of $100 \%$ in each group (Table 4A).

The one-way analysis of variance (ANOVA), indicated that Fourier harmonics 2, 3, 7, 8, 9, 12, 13, 16, 17 and 18 were significant (Table 5) and were the shape descriptors that showed the greater discriminant power between the groups (Figure 2G). The linear discriminant analysis, that gave significant differences (Wilk's lambda $=0.2887$; approximate $\left.F_{(19,38)}=4.9285 ; P<0.001\right)$, assigned a prediction probability of $92.86 \%$ and $100 \%$ for the Atlantic and
Mediterranean groups respectively (Table 6A). The quadratic discriminant analysis, that also gave significant differences (Chi-Square test: $\chi^{2}{ }_{(190)}=312.17 ; \quad P<0.001$ ), gave a null PMC and NIMC, therefore it classified the sagittae correctly with a prediction of $100 \%$ for both groups (Table 6B).

\section{DISGUSSION}

Multivariate morphometric analyses, as used in this study, are a good quantitative tool to identify intraspecific (size and shape) variation of sagittal otolith morphology related to ecological differences of the three species considered.

Otolith morphology analyses have been used to compare the shape from morphometric data in other species of fishes and the results of the studies were not only similar in separating groups from distinct geographical areas but also, principally, between stocks (Messieh et al., 1989; Castonguay et al., 1991; Friedland \& Reddin, 1994). However, no study has been carried out related to the environmental effects that can affect the otolith morphology of samples from different geographical origins and yet these can be viewed as evidence of genetic separation of units of populations or stocks. The otolith ontogenic variation for size was corrected considering a total length. However, other changes related to age, such as weight increase and a more complicated ornamentation, were not corrected. Any introduced error though was probably not very important because the probability of classification error was very low.

Our results indicate that the joint analysis of the whole otolith and sulcus acusticus morphometric measurements are very appropriate for determining the geographical origin of the otoliths. Using both PCA and discriminant analyses, a clear differentiation was obtained for Merluccius gayi and M. merluccius. In both species, the discriminant analysis predicts that all the sagittae can be correctly assigned within each one of the groups studied. However, it is a little less effective at differentiating between the two groups of $M$. hubbsi.

The PCA carried out indicates that a large part of the variability is concentrated in the first component (between $65.9 \%$ and $82.22 \%$ ). All the coefficients are positive and almost all the morphometric variables are highly correlated to this component. It therefore represents the component of relative size that is not linked with individual allometric growth. The first component further indicates that the largest intragroup variability is established in relation to the relative size of the otolith, as happens when the sagittae are compared at the interspecific level (Lombarte \& Lleonart, 1993; Torres et al., 1999). The intraspecific otolith size differences are very closely linked to variations in environmental parameters, especially temperature (Casselman, 1990; Gauldie \& Nelson, 1990). In the three studied species the otolith intraspecific size variability could be due to oceanographic differences related to their differential geographical origin.

In the case of $M$. gayi, the specimens from the coast of Peru are located in a temperature range between 10 and $19^{\circ} \mathrm{C}$ in normal years or between 14 and $22^{\circ} \mathrm{C}$ for the years in which the 'El Niño southern oscillation' (ENSO) 
takes place (Espino et al., 1995). On the other hand, the specimens from Chile (M. gayi gayi), of smaller otolith relative size, are distributed in colder waters with bottom temperatures between 8 and $11^{\circ} \mathrm{C}$ (Aguayo-Hernández, 1995). In addition, there is no contact between the two groups due to the narrowing of the continental shelf in the south-western Pacific and to the presence of hydrogen sulphide in deep layers between latitudes of $13^{\circ}$ and $19^{\circ}$ South (Inada, 1981). These factors act as a biogeographical barrier, preventing the mixture of individuals from different origins in both of the two studied areas.

Merluccius merluccius otolith variability can also be explained by the existing oceanographical differences between north-eastern Atlantic and Mediterranean areas (Casey \& Pereiro, 1995; Morales-Nin et al., 1998b). The otoliths from the Mediterranean, that have a larger relative size, have developed in a more homogeneous and stable environment (Recasens et al., 1998). Below the thermocline the temperatures remain between 12 and $14^{\circ} \mathrm{C}$ throughout the whole year (Salat, 1996). In the north-eastern Atlantic, the European hake lives in colder waters with a larger seasonal variability (between 10 and $13^{\circ} \mathrm{C}$ ) (Casey \& Pereiro, 1995).

In the case of M. hubbsi, the PCA indicates that the two analysed groups do not separate into a morphological gradient (size and shape) for the sagittae otoliths in such an evident way as in the other two species, although the otoliths of the San Matias Gulf are relatively larger than those of the Argentinian-Uruguayan Common Fishing Zone. Several factors can explain this result. In the distribution area for the species, the sea temperature shows variations between latitudes of greater than $2-4^{\circ} \mathrm{C}$, with the northern waters being warmer than the southern ones (Provost et al., 1992; Torres et al., 1996). However, in the San Matias Gulf there is a thermohaline front that generates warmer and saltier waters than those corresponding to the shelf of the same latitude (Di Giácomo et al., 1993). Also, the existence of seasonal migrations (trophic and reproductive) of this species (Podestá, 1989) implies that the group of specimens from the north coexists in a high proportion with specimens from other reproduction areas located more to the south, as indicated by the results of Torres et al. (1996).

For all three species, the second principal component explains a much smaller variability than the first component (between 6.04\% and 12.19\%). In the three species, the intraspecific variability is related to the shape (especially the width) and the relative size of the sulcus acusticus. These measurements do not, though, order the groups geographically in any of the three species because the observed differences express an individual variability factor that is related to the ontogenetic changes that take place in the relationship between the area of the sulcus acusticus and the otolith, which are related to depth variations and diet changes with age (Lombarte, 1992).

The study of sagittae external outlines (shape analysis), through Fourier harmonics, indicates that they can be suitable to study the geographical differences of the sagittae at an intraspecific level. Harmonics 2, 3, 8, 9, 12 and 13, that appear more often as shape discriminants, are the same ones that contribute to the discrimination of the sagittae at the interspecific level. These shape discriminants indicate differences in the ratios between the length and width of the otoliths and the presence of excisurae in their outlines that produce an increase of the relative perimeter (Lombarte \& Castellón, 1991; Torres, 1997). The agreement of the intraspecific and interspecific analyses of shape suggests that, as happens in the interspecific studies, the observed differences in shape are a reflection of the genetic distance between the analysed groups.

The results of the discriminant analyses support this hypothesis. Thus, the sagittae otoliths that do not have a null probability of mistaken classification (PMC) correspond to the species M. hubbsi, that is characterized by forming a single genetic population (Roldán, 1995), with important migrations that connect the different geographical areas where they occur and the adult populations reproduce. On the other hand, M. merluccius, that has a null PMC for the predicted classification in the quadratic discriminant function, shows genetic differences between the north-eastern Atlantic and the Mediterranean populations (Roldán et al., 1998). In the case of $M$. gayi, that has a non-null PMC but a very low predicted classification in the quadratic discriminant function, studies do not exist concerning the intraspecific genetic variability, although the hypothesis of the existence of genetic differences between the two groups is very probably due to their geographical isolation and the morphological differences found between both, that have led to them being considered as two subspecies (Inada, 1981; Cohen et al., 1990).

We can conclude that the combined use of morphometric variables (size and shape) and external outlines (shape analysis), allowed the importance of otolith relative size and shape variability in the intraspecific classification to be determined. The otolith variability shown is in agreement with genetic (population and stocks) and environmental (temperature) effects on otolith growth observed by Lombarte \& Lleonart (1993) and Torres et al. (1999). The use of sulcus acusticus dimensions (expressed by the second component in a PCA) appears to be an important tool for determining otolith morphology.

Vilma Ojeda (Instituto del Mar, Peru), David Garland (Universidad Arturo Prat, Iquique, Chile), Carmen Piñeiro (Instituto Español de Oceanografía, Vigo, Spain), Pere Oliver (FAO, Rome, Italy), Laura Recasens (Institut de Ciències del Mar, Barcelona, Spain), Walter Norbis (Instituto Nacional de Pesca, Montevideo, Uruguay), Herbert Nión (Instituto Nacional de Pesca, Montevideo, Uruguay) and Edgardo Di Giácomo (Instituto de Biología Marina-Alte. Storni, Rio Negro, Argentine) are thanked for their invaluable help in making the otolith samples available. Sergi Tudela is thanked for comments on the manuscript. This work was supported by the DG XIV of the EU. Gabriel Torres' contribution was funded under a doctoral fellowship grant supported by the International Co-operation Hispanian Agency (AECI) and the Hispanian-American Cooperation Catalonian Institute (ICCI) and under the postdoctoral fellowship supported by the Consejo Superior de Investigaciones Científicas (CSIC), Spain.

\section{REFERENCES}

Aguayo-Hernández, M., 1995. Biology and fisheries of Chilean hakes (Merluccius gayi and australis). In Hake: fisheries, ecology and markets (ed. J. Alheit and T.J. Pitcher), pp. 305-337. London: Chapman \& Hall Book Series. 
Campana, S.E. \& Casselman, J.M., 1993. Stock discrimination using otolith shape analysis. Canadian Fournal of Fisheries and Aquatic Sciences, 50, 1062-1083.

Casey, J. \& Pereiro, J., 1995. European hake (Merluccius merluccius) in the north-east Atlantic. In Hake: fisheries, ecology and markets (ed. J. Alheit and T.J. Pitcher), pp. 125-147. London: Chapman \& Hall Book Series.

Casselman, J.M., 1990. Growth and relative size of calcified structures of fish. Transactions of the American Fisheries Society, 119, 673-668.

Casselman, J.M., Collins, J.J., Crossman, E.T., Ihssen, P.E. \& Splangler, G.R.S., 1981. Lake whitefish (Coregonus clupeaformis) stocks of the Ontario waters of Lake Huron. Canadian Fournal of Fisheries and Aquatic Sciences, 38, 1772-1789.

Castonguay, M., Simard, P. \& Gagnon, P., 1991. Usefulness of Fourier analysis of otolith shape for Atlantic mackerel (Scomber scombrus) stock discrimination. Canadian Fournal of Fisheries and Aquatic Sciences, 48, 296-302.

Cohen, D.M., Inada, T., Iwamoto, T. \& Scialabba, N., 1990. Gadiformes fishes of the world (Other Gadiformes). An annotated and illustrated catalogue of cods, hakes, grenadiers and other gadiform fishes known to date. FAO Fish Synopsis, $125,1-442$.

Côté, G., Lamoureux, P., Boulva, J. \& Lacroix, G., 1980. Séparation des populations de hareng de l'Atlantique (Clupea harengus) de l'estuaire du Saint Laurent et de la péninsule gaspésienne. Canadian Fournal of Fisheries and Aquatic Sciences, 37, 66-71.

Di Giácomo, E.E., Calvo, J., Perier, M.R. \& Morriconi, E., 1993. Spawning aggregations of Merluccius hubbsi, in Patagonian waters: evidence for a single stock? Fisheries Research, 16, 9-16.

Espino, M., Castillo, R. \& Fernández, F., 1995. Biology and fisheries of Peruvian hake (Merluccius gayi peruanus). In Hake: fisheries, ecology and markets (ed. J. Alheit and T.J. Pitcher), pp. 339-363. London: Chapman \& Hall Book Series.

FAO, 1995. FAO Yearbook. Fishery Statistics. Catches and landings, vol. 76. Rome: FAO.

Friedland, K.D. \& Reddin, D.G., 1994. Use of otolith morphology in stock discriminations of Atlantic salmon (Salmo salar). Canadian Fournal of Fisheries and Aquatic Sciences, 51, 91-98.

Gauldie, R.W. \& Nelson, D.G.A., 1990. Otolith growth in fishes. Comparative Biochemistry and Physiology, 97, 119-135.

Grant, W.S., Leslie, R.W. \& Becker, I.I., 1987. Genetic stock structure of the southern African hakes Merluccius capensis and Merluccius paradoxus. Marine Ecology of Progress Series, 41, 9-20.

Inada, T., 1981. Studies on the merluccid fishes. Bulletin of Far Seas Research Laboratory (Shimizu), 18, 1-172.

Jolicoeur, P., 1963. The multivariate generalisation of the allometry equation. Biometrics, 19, 497-499.

Levi, D., Andreoli, M.G., Arneri, E., Giannetti, G. \& Rizzo P., 1994. Otolith readings as a tool for stock identification. Fisheries Research, 20, 97-107.

Lombarte, A., 1992. Changes in otolith area: sensory area ratio with body size and depth. Environmental Biology of Fishes, 33, 405-410

Lombarte, A. \& Castellón, A., 1991. Interspecific and intraspecific variability in the genus Merluccius as determined by image analysis. Canadian Fournal of Zoology, 69, 2442-2449.

Lombarte, A. \& Lleonart, J., 1993. Otolith size changes related with body growth, habitat depth and temperature. Environmental Biology of Fishes, 37, 297-306.
MacLeod, N. \& Kitchell, J.A., 1990. Morphometrics and evolutionary inference: a case study involving ontogenetic and developmental aspects of foraminiferal evolution. In Proceedings of the Michigan Morphometrics Workshop (ed. F.J. Rohlf and F. Bookstein), pp. 283-299. Michigan: University of Michigan, Museum Ann Arbor.

Messieh, S.N., MacDougall, C. \& Claytor, R., 1989. Separation of Atlantic herring (Clupea harengus) stocks in the southern Gulf of St. Lawrence using digitised otolith morphometrics and discriminant function analysis. Canadian Technical Report of Fisheries and Aquatic Sciences, 1647, 1-22.

Misra, R.K., 1985. Quadratic discriminant analysis with covariance for stock delineation and population differentiation: a study of beaked redfishes (Sebastes mentella and S. fasciatus). Canadian Fournal of Fisheries and Aquatic Sciences, 42, 1672-1676.

Morales-Nin, B., Lombarte, A. \& Japón, B., 1998a. Approaches to otolith age determination: image signal treatment and age attribution. Scientia Marina, 62, 247-256.

Morales-Nin, B., Torres, G.J., Lombarte, A. \& Recasens, L., 1998b. Otolith growth and age estimation on European hake Merluccius merluccius. Fournal of Fish Biology, 53, 1155-1168.

Nolf, D., 1985. Otolith piscium. In Handbook of paleoichthyology, vol. 10 (ed. H.P. Schultze), pp. 1-145. Stuttgart and New York: Gustav Fisher Verlag.

O'Higgins, P. \& Williams N.W., 1987. An investigation into the use of Fourier coefficients in characterising cranial shape in primates. Fournal of Zoology, 211, 409-430.

Podestá, G., 1989. Migratory pattern of Argentine hake Merluccius hubbsi and oceanic processes in the south-western Atlantic Ocean. Fisheries Bulletin, 88, 167-177.

Provost, C., Garcia, O. \& Garcon, V., 1992. Analysis of satellite sea surface temperature time series in the Brazil-Malvinas current confluence region: dominance of the annual and semi-annual periods. Fournal of Geophysics Research, 97(C11), $17841-17858$.

Recasens, L., Lombarte, A., Morales-Nin, B. \& Torres, G.J., 1998. Spatio-temporal variability in the population structure of the European hake, Merluccius merluccius, in the NW Mediterranean. Journal of Fish Biology, 53, 387-401.

Roldán, M.I., 1991. Enzymatic polymorphism in the Argentinian hake, Merluccius hubbsi Marini, of the Argentinian continental shelf. Fournal of Fish Biology, 39, Supplement A, $53-59$.

Roldán, M.I. et al., 1998. Population genetic structure of European hake, Merluccius merluccius. Heredity, 81, 327-334.

Salat, J., 1996. Review of hydrographic environmental factors that may influence anchovy habitats in north-western Mediterranean. Scientia Marina, 60, Supplement 2, 21-32.

Torres, G.J., 1997. Variación intraespecifica e interespecífica de la morfología y de las pautas del crecimiento del otolito sagitta en el género Merluccius (Gadiformes: Teleostei). $\mathrm{PhD}$ thesis, Polytechnic University of Catalonia, Barcelona, Spain.

Torres, G.J., Lombarte, A. \& Morales-Nin, B., 1999. Variability of the sulcus acusticus in the sagittal otolith of the genus Merluccius. In Proceedings of the Second International Symposium on Fish Otolith Research and Application, Bergen, Norway, 20-25 June 1998. Fisheries Research, in press.

Torres, G.J., Norbis, W. \& Lorenzo, M.I., 1996. Variations in the measures of argentine hake (Merluccius hubbsi) rings otoliths during their first-year: evidence for stocks separation? Scientia Marina, 60, 331-338.

Yefanov, V.N. \& Khorevin, L.D., 1979. Distinguishing populations of pink salmon, Oncorhynchus gorbuscha, by the size of their otoliths. Fournal of Ichthyology, 19, 142-145.

Submitted 26 April 1999. Accepted 7 September 1999. 